Original Article

\title{
A study on the physical fitness of children with juvenile rheumatoid arthritis
}

\author{
Hyo-Jeong Kwon, PT, MS'1), You Lim Kim, PT, MS'1), Hyun Soo Lee, PT, BS ${ }^{1)}$, \\ SuK Min LEE, PT, $\mathrm{PhD}^{1)^{*}}$ \\ 1) Department of Physical Therapy, Sahmyook University: 26-21 Gongneung2-dong, Nowon-gu, \\ Seoul 139-742, Republic of Korea
}

\begin{abstract}
Purpose] This study was conducted to assess the physical fitness of children with juvenile rheumatoid arthritis (JRA). [Subjects and Methods] In total, 26 children with juvenile rheumatoid arthritis (JRA) and 25 healthy controls participated in this study. Using the physical fitness measurement instruments, the Inbody 720 and Quark b2, the elements of physical fitness that were assessed included muscular strength, muscular endurance, flexibility, lung capacity, and body composition. [Results] The results revealed significant differences in muscular strength, muscular endurance, lung capacity, body composition, functional ability, and health-related quality of life between the children with juvenile rheumatoid arthritis (JRA) and the control group. [Conclusion] These results suggested that children with juvenile rheumatoid arthritis (JRA) have inferior physical fitness when compared to healthy children. The present study was conducted to develop an accurate evaluation standard to assess the physical fitness of children with juvenile rheumatoid arthritis (JRA).

Key words: Juvenile rheumatoid arthritis, Physical fitness
\end{abstract}

(This article was submitted Jul. 19, 2016, and was accepted Nov. 18, 2016)

\section{INTRODUCTION}

Juvenile idiopathic arthritis is officially known as juvenile rheumatoid arthritis (JRA). Roth et al. previously reported that children with polyarticular JRA experienced faster progression of muscular atrophy, resulting in subtle changes in juvenile skeleton development ${ }^{1)}$. They stated that the muscle loss in juveniles affected their physical strength ${ }^{2)}$ and the amount of muscle loss was correlated with bone density and muscle strength ${ }^{3}$. According to those researchers, the level of physical activity, which is related to body weight, enables the anticipation of overall skeletal sizes. Juveniles with rheumatoid arthritis were easily fatigued as a result of such physical symptoms, and their physical activities were greatly restricted. According to existing research, the level of physical activity, overall energy consumption, and active energy consumption in children with JRA are lower than those in healthy children in the same peer group. Only $23 \%$ of children with JRA exhibited a physical activity level of at least $1 \mathrm{~h} / \mathrm{day}^{4}$ ). Additionally, their aerobic, anaerobic, and functional abilities for performing their daily routines were poorer than those of healthy children. Aerobic ability is believed to have a significant correlation with the level of physical activity ${ }^{5}$. Physical fitness is related to daily physical activity, nutritional habits, and genetic factors, and it is a significant indicator of health status. According to the existing literature, both physical fitness and physical activity of children with JRA are lower than those of healthy children in the same peer group, when cardiovascular and muscle endurance are assessed ${ }^{6}$. Especially, Study of Teresa $M$ et al. reveled that juvenile arthritis has included joint inflammation, pain, stiffness, and limited mobility ${ }^{7}$.

Studies $^{8)}$ evaluating the physical fitness of juvenile patients with rheumatoid arthritis and emphasizing the importance of exercise intervention have been performed, and research investigating the effects of aerobic exercises, muscle exercise,

*Corresponding author. Suk Min Lee (E-mail: leesm@syu.ac.kr)

(C2017 The Society of Physical Therapy Science. Published by IPEC Inc.

This is an open-access article distributed under the terms of the Creative Commons Attribution Non-Commercial No Derivatives (by-nc-nd) License $<$ http://creativecommons.org/licenses/by-nc-nd/4.0/>. 
and other variables ${ }^{9,10)}$ has also been reported. However, only a few studies ${ }^{6}$ ) have accurately evaluated the 5 elements of physical fitness by using modern measuring devices. Although a study on health-related physical fitness has been reported, the differences in the current physical fitness of children with JRA compared with that 20 years ago remains to be elucidated. Therefore, Physical data of Physical therapy for juvenile rheumatoid arthritis need to prepare. Accordingly, this study investigated the physical fitness of children with JRA to help create safe and accurate evaluation criteria for comparisons with healthy children, to provide information necessary to develop exercise interventions, and to help these patients maintain healthy daily lives.

\section{SUBJECTS AND METHODS}

For this research experiment, 26 children with JRA and 25 healthy children were selected. The inclusion criteria for the patients with JRA included an age of 8 to 16 years; a diagnosis of JRA; the ability to move independently, communicate, and follow instructions for research tests; and consent to participate in the experiment after being told about its purposes. Individuals with a medically unstable condition (presence of a heart or lung disease, or hospitalization for disease exacerbation within 4 weeks before the test) and those who were unable to perform the physical fitness tests to assess muscle strength, muscle endurance, flexibility, and lung capacity were excluded. The subjects included in the control group were similar-aged, healthy schoolchildren. Individuals with heart or lung disease, those participating in exercise or sports programs regularly at least 3 times a week, athletes, and children who could not perform the physical fitness tests to assess muscle strength, muscle endurance, flexibility, and lung capacity were excluded from the control group.

The 51 research subjects were children whose ages ranged from 8 to 16 years, who understood the research purposes, and proactively expressed their intent to participate in the experiment. The experiment was approved by the Institutional Review Board of Sahmyook University. All of the subjects provided written informed consent prior to study enrollment. Before testing, the general characteristics of the children including their gender, age, body weight, height, and duration of disease (for the individuals with JRA) were recorded. The physical fitness of the 51 participants was recorded. The participants and their parents were instructed to answer a survey to record their functional abilities and health-related quality of life. All measurements were performed on the same day of testing.

The physical therapist involved in this research explained the physical fitness measurements to the participants to ensure that they understood possible problems that could arise during the testing.

Muscle strength (grasping power) was measured using a digital grip dynamometer (Grip-D, T.K.K.5401, TAKEI, Japan). The participants were seated with their arms placed naturally on the desk. With their elbows bent approximately $90^{\circ}$, the participants adjusted the width of the handles by extending their wrists by $10-15^{\circ}$, gripped the handles by bending the second joints of the fingers by $90^{\circ}$, and pulled the handles with the maximum possible force for $5 \mathrm{~s}$. The measurement, which was recorded to the nearest $0.1 \mathrm{~kg}$, was performed twice, and the better result of the 2 measurements was retained. A 1-min break was permitted between the measurements to minimize fatigue. The measurement tool's reliability as assessed by the intraclass correlation coefficient (ICC) was 0.97-0.9811).

Muscle strength (back muscle strength) was measured using a back muscle dynamometer (BACK-D, T.K.K.5402, TAKEI). The participants stood on the foothold of the dynamometer by placing the metal ring string in the middle of their feet, with their feet positioned about $15 \mathrm{~cm}$ apart, and folded their upper body $30^{\circ}$ forward to adjust the metal ring string length and secure it. The participants bent forward at the waist, unbent their knee joints, opened their chests to bring their handles parallel to the floor, and pulled with their maximum strength for $5 \mathrm{~s}$. The measurement, which was recorded to the nearest $0.1 \mathrm{~kg}$, was performed twice, with the better result of the 2 measurements retained. A 1-min break was permitted between the measurements to minimize fatigue. The measurement tool's reliability as assessed by the ICC was $0.93-0.9712$ ).

For the muscle endurance (sit-up) measurement, the participants lied down on their backs and bent their knees until their heels were $30 \mathrm{~cm}$ from their hips. They raised both hands up toward the opposite shoulders, so that their arms crossed. During the measurement, they were instructed to touch their elbows to their knees, and when they reclined, to touch their shoulders to the mat. The 1-min sit-up performance was recorded for each participant. The measurement method's reliability as assessed by the ICC was $0.91^{13)}$.

The flexibility (bending forward) of the participants was measured using a digital trunk forward flexion meter (FLEXIOND, T.K.K.5403, TAKEI). The participants took off their shoes and stood on the 40-cm-high table, with their feet separated by approximately $5 \mathrm{~cm}$. The subjects fully straightened their knees, bent their torsos forward, and pushed the meter board downward with the end of the middle fingers of both hands. They maintained this posture for $1 \mathrm{~s}$ for recording. The measurement was performed 3 times and recorded to the closest $0.1 \mathrm{~cm}$, and the best performance of the 3 trials was taken as the measurement. A 1-min break was permitted between the measurements to minimize fatigue. The measurement tool's reliability as assessed by the ICC was $0.99^{14)}$.

Lung capacity was measured using a lung capacity measuring instrument (Quark b $b^{2}$, COSMED, Italy). The lung capacity measurement followed the recommendation of the American Thoracic Society. The participants were seated with their nose blocked by forceps, and a mouthpiece was placed in each participant's mouth to prevent air leakage through the nose and mouth. The subjects were instructed to inhale to their full lung capacity before exhaling, and then to rapidly exhale. The measurement was performed 3 times, and the best result among the measurements was recorded. A 1-min break was taken 
after each measurement to minimize fatigue. In this study, the forced vital capacity (FVC) and forced expiratory volume in $1 \mathrm{~s}$ (FEV1) were obtained from the measurements. FVC refers to the capacity of exhalation to the largest possible extent at the maximal effort following maximal inhalation. FEV1 is a measure of the amount of air expelled during the first second of forced exhalation, and it is commonly used to evaluate lung capacity. The ICC of the measurement was $0.99^{15}$ ).

Body composition was measured using a body composition analyzer (Inbody 720, BIOSPACE, Korea) indoors under a controlled temperature of $23-28^{\circ} \mathrm{C}$. The skeletal muscle mass and body fat percentage were obtained in this study. The subjects removed their socks, sufficiently cleaned their hands and feet with electrolyte tissues without wearing any metal, stepped on the electrode of the meter foothold, and held the electrode bars naturally for 1 measurement. The measurement tool's reliability as assessed by the ICC was $0.99^{16)}$.

All of the analytical and statistical processing in this study was performed using SPSS ver. 21.0. The KolmogorovSmirnov test was used to assess the normality of the general characteristics of the subjects and the measured variables. Through technical statistical analysis, the general characteristics of the participants such as gender, age, height, weight, and body mass index (BMI) were analyzed. An independent-samples t-test was employed to identify differences in physical fitness between the children with JRA and the control group. The Scheffe test was used for the post hoc analysis. For all of the analyses, the level of statistical significance was set at $\mathrm{p}<0.05$.

\section{RESULTS}

The general characteristics of the research participants are presented in Table 1 . The study sample was comprised of 26 children with rheumatoid arthritis and 25 healthy controls. Of the 26 children with RA 15 were male (57.7\%), and 11 were female (42.3\%); 5 children were aged 8-10 years, 12 children were 11-13 years old, and 9 children were 14-16 years old. Of the 25 children in the control group, $15(60 \%)$ were male, and $10(40 \%)$ were female; 7 children were $8-10$ years old, 9 children were 11-13 years old, and 9 children were 14-16 years old. No significant differences in age distribution were noted between the groups. The mean age, height, weight, BMI, and duration of illness of the children with JRA were 12.58 years, $141.66 \mathrm{~cm}, 40.05 \mathrm{~kg}, 19.43 \mathrm{~kg} / \mathrm{m}^{2}$, and 53.62 months, respectively. The mean age, height, weight, and BMI of the healthy controls were 12.32 years, $151.61 \mathrm{~cm}, 45.30 \mathrm{~kg}$, and $19.86 \mathrm{~kg} / \mathrm{m}^{2}$, respectively, and only height was significantly different between the groups.

The patients with JRA and the healthy controls exhibited differences in physical fitness (Table 2). The children in the JRA group were shorter and lighter in body weight, and they displayed differences in variables such as gender, age, and body mass that are believed to affect muscle strength and endurance. Therefore, to narrow the age-specific gaps, we divided the participants into the 3 age groups of 8-10,11-13, and 14-16 years in an effort to divide the children by grade (lower elementary, higher elementary, and middle school grades).

The muscle strength of the juveniles with rheumatoid arthritis was measured by assessing grasping power and back strength. It was found that the children in the control group displayed greater grasping power and back strength than the patients with rheumatoid arthritis. Grasping power was significantly different between the children with JRA and those in the control group in all age groups, and back strength was significantly different for the entire cohort and the 14-16 year-old age group.

When the muscle endurance of the children was assessed, the children with JRA performed an average of 17.38 sit-ups during the measurement, versus an average of 25.60 sit-ups for the healthy controls.

The lung capacity testing of the children revealed that the FVC and FEV1 of the children with RA were 2.33 and $1.99 \mathrm{~L}$, respectively, compared to 2.93 and $2.59 \mathrm{~L}$, respectively, for the healthy controls. The FEV was significantly different between the children with JRA and the healthy controls in all of the age groups excluding the 14-16 year-old age group, whereas FEV1 was significantly different in all of the age groups.

The measurements of body composition revealed that the participants in the rheumatoid arthritis group had a body fat

Table 1. General characteristics of the research subjects

\begin{tabular}{lccr}
\hline & $\begin{array}{c}\text { JRA group } \\
(\mathrm{n}=26)\end{array}$ & $\begin{array}{c}\text { Normal group } \\
(\mathrm{n}=25)\end{array}$ & $\mathrm{t}(\mathrm{p})$ \\
\hline Gender (male/female) & $15 / 11$ & $15 / 10$ & $-0.166(0.868)$ \\
Age $($ years $)$ & $12.58 \pm 2.63^{\mathrm{a}}$ & $12.32 \pm 2.56$ & $0.354(0.725)$ \\
Height $(\mathrm{cm})$ & $141.66 \pm 17.25$ & $151.61 \pm 14.25$ & $-2.241(0.030)$ \\
Weight $(\mathrm{kg})$ & $40.05 \pm 10.73$ & $45.30 \pm 11.91$ & $-1.655(0.104)$ \\
BMI $\left(\mathrm{kg} / \mathrm{m}^{2}\right)$ & $19.43 \pm 3.06$ & $19.86 \pm 3.36$ & $-0.481(0.632)$ \\
Duration of illness (months) & $53.62 \pm 6.19$ & & \\
\hline
\end{tabular}

JRA: juvenile rheumatoid arthritis; BMI: body mass index

${ }^{\mathrm{a}}$ mean \pm standard deviation 
percentage of $26.73 \%$ and a skeletal muscle mass of $14.85 \mathrm{~kg}$, versus values of $19.00 \%$ and $19.63 \mathrm{~kg}$, respectively, for the healthy controls. Significant differences were observed in body fat percentage for the 14-16 year-old age group and in skeletal muscle mass for all age groups. Based on the post-experiment analysis, the FVC and FEV1 were found to be higher in the 8-10 and 11-13-year-old age groups for patients with JRA than in the 8-10 year-old group. Meanwhile, skeletal muscle mass was higher in the 14-16 year-old age group than in the 8-10- and 11-13 year-old groups. In the control group, grasping power, back strength, FVC, FEV1, and skeletal muscle mass were greater in the 14-16 year-old age group than in the 8-10- and 11-13 year-old groups.

\section{DISCUSSION}

In a study by Lindehammar and Lindvall ${ }^{17)}$, muscle strength tended to increase with increasing muscle mass, and muscle fiber was said to be activated according to the degree of coordination in muscle cross-sections and activated muscle fibers. This indicated that an increase in muscle cross-sectional area improved muscle strength, and since the muscle strength of the children with JRA was poorer than that of the healthy controls, their patterns of muscle fiber changes differed from those of the control group. Therefore, delays in growth and lower levels of physical activity can be said to weaken the muscle strength of patients with JRA. The current study also illustrated that the measures of muscle strength including grasping power, back strength, and skeletal muscle mass were poorer in children with JRA than in the controls. In a study by Klepper et al. ${ }^{6}$, significant differences were found in muscle endurance between healthy children and patients with JRA. Similar to the present study, that study used the sit-up method to assess muscle endurance, but no age groups were created. In a study by Nascimento et al. ${ }^{18)}$ that utilized upper body curl-ups to measure muscle endurance, no significant difference was found between the groups. Therefore, it appears that muscle endurance has been assessed using different measurement and age grouping methods in different studies. Follow-up studies will need to further examine age-specific muscle endurance characteristics.

The present study identified no significant difference in the flexibility of children with JRA relative to those in the control group; both groups displayed flexibility close to the age-specific average baselines. Patients with JRA commonly complain about pain, morning stiffness, and limited activity due to joint contracture ${ }^{19)}$. Thus, it was expected that flexibility of the

Table 2. Comparison of physical fitness between the groups (continued) $(\mathrm{N}=51)$

\begin{tabular}{|c|c|c|c|c|c|}
\hline & & Age & JRA group $(n=26)$ & $\begin{array}{l}\text { Normal group } \\
\quad(\mathrm{n}=25)\end{array}$ & $\mathrm{t}(\mathrm{p})$ \\
\hline \multirow{12}{*}{$\begin{array}{l}\text { Lung } \\
\text { capacity }\end{array}$} & \multirow{6}{*}{ FVC (L) } & $8-10$ years $(\mathrm{A})$ & $1.58 \pm 0.15^{\mathrm{a}}$ & $2.12 \pm 0.36$ & $-3.558(0.007)$ \\
\hline & & $11-13$ years $(B)$ & $2.31 \pm 0.34$ & $2.98 \pm 0.36$ & $-4.315(0.000)$ \\
\hline & & $14-16$ years $(\mathrm{C})$ & $2.77 \pm 0.93$ & $3.52 \pm 0.58$ & $-2.048(0.057)$ \\
\hline & & All & $2.33 \pm 0.72$ & $2.93 \pm 0.72$ & $-2.992(0.004)$ \\
\hline & & $\mathrm{F}(\mathrm{p})$ & $6.431(0.006)$ & $18.823(0.000)$ & \\
\hline & & Post hoc analysis & $\mathrm{A} \mid \mathrm{B} \mathrm{C}$ & $\mathrm{A}|\mathrm{B}| \mathrm{C}$ & \\
\hline & \multirow{6}{*}{ FEV1 (L) } & $8-10$ years (A) & $1.44 \pm 0.09$ & $1.82 \pm 0.34$ & $-2.793(0.026)$ \\
\hline & & $11-13$ years $(B)$ & $2.05 \pm 0.34$ & $2.65 \pm 0.38$ & $-3.761(0.001)$ \\
\hline & & $14-16$ years $(\mathrm{C})$ & $2.22 \pm 0.80$ & $3.13 \pm 0.63$ & $-2.707(0.016)$ \\
\hline & & All & $1.99 \pm 0.58$ & $2.59 \pm 0.70$ & $-3.322(0.002)$ \\
\hline & & $\mathrm{F}(\mathrm{p})$ & $3.595(0.044)$ & $14.933(0.000)$ & \\
\hline & & Post hoc analysis & $\mathrm{A} \mid \mathrm{B} \mathrm{C}$ & $\mathrm{A}|\mathrm{B}| \mathrm{C}$ & \\
\hline \multirow{11}{*}{$\begin{array}{l}\text { Body } \\
\text { composition }\end{array}$} & \multirow{5}{*}{$\begin{array}{l}\text { Body fat } \\
\text { percentage (\%) }\end{array}$} & $8-10$ years (A) & $23.42 \pm 10.14$ & $18.50 \pm 5.62$ & $1.084(0.304)$ \\
\hline & & $11-13$ years $(B)$ & $24.98 \pm 9.30$ & $21.60 \pm 7.23$ & $0.904(0.378)$ \\
\hline & & $14-16$ years $(\mathrm{C})$ & $30.91 \pm 14.44$ & $16.79 \pm 9.33$ & $2.465(0.025)$ \\
\hline & & All & $26.73 \pm 11.45$ & $19.00 \pm 7.66$ & $2.822(0.007)$ \\
\hline & & $F(p)$ & $0.944(0.404)$ & $0.900(0.421)$ & \\
\hline & \multirow{6}{*}{$\begin{array}{l}\text { Skeletal muscle } \\
\text { mass }(\mathrm{kg})\end{array}$} & $8-10$ years $(\mathrm{A})$ & $9.06 \pm 1.30$ & $12.36 \pm 2.83$ & $-2.409(0.037)$ \\
\hline & & $11-13$ years $(\mathrm{B})$ & $14.63 \pm 3.12$ & $20.29 \pm 3.26$ & $-4.034(0.001)$ \\
\hline & & $14-16$ years $(\mathrm{C})$ & $18.36 \pm 5.72$ & $24.63 \pm 3.60$ & $-2.787(0.013)$ \\
\hline & & All & $14.85 \pm 5.12$ & $19.63 \pm 5.90$ & $-3.096(0.003)$ \\
\hline & & $\mathrm{F}(\mathrm{p})$ & $8.532(0.002)$ & $27.912(0.000)$ & \\
\hline & & Post hoc analysis & $\mathrm{AB} \mid \mathrm{C}$ & $\mathrm{A}|\mathrm{B}| \mathrm{C}$ & \\
\hline
\end{tabular}

${ }^{a}$ mean \pm standard deviation

JRA: juvenile rheumatoid arthritis; FVC: forced vital capacity; FEV1: forced expiratory volume in $1 \mathrm{~s}$ 
children with JRA would be lower than that of healthy children, but our results differed from the findings of other studies. In this study, the selected subjects with JRA did not have limited range of motion in the wrist and distal ankle because of pain, and they rarely exhibited limitations in flexion contracture, and waist and chest flexibility. For this reason, the children with rheumatoid arthritis displayed no significant differences from the control group in forward bending, which is affected by hip or knee joint limitations.

It has been reported that children with JRA exhibit a slower pace of FVC and maximum aerobic respiration due to weakened respiratory muscles rather than due to more fundamental lung diseases ${ }^{20)}$. A study by Lee and Jung ${ }^{21)}$ reported changes in physical measurements such as age, height, weight, and body surface area as a result of changes during the growth period. The lung function measurement displayed the strongest correlation with height among the variables, and the lung function measurement was reported to increase according to age and weight. Also, Study of sleep for juvenile arthritis detect that sleep disturbances in juvenile arthritis children may stem from underlying sleep disorders such as sleep disordered breathing and periodic limb movements rather than disease-related symptoms ${ }^{7,22)}$. Our study also uncovered significant correlations among grasping power, back strength, muscle endurance, and lung capacity. When respiratory muscle-related muscle endurance and lung capacity were measured, the juveniles with rheumatoid arthritis exhibited significant differences from healthy children, and they were shorter. Accordingly, their lung capacity was significantly different from that of healthy children, and significant differences were identified after differentiating the subjects based on normal and abnormal lung capacity. However, the 14-16 year-old children with JRA exhibited no significant difference in height compared to the healthy controls, and they displayed no significant difference in FVC.

According to a study by Reilly ${ }^{23}$, changes in body composition must be investigated, as these changes can affect the prognosis of diseases. However, the body composition of children with JRA is unknown because it is difficult to evaluate this variable in growing children. In addition, increases in inflammatory cytokine production and skeletal muscle inflammation have been noted to increase obesity ${ }^{24}$. In this study, there was a high the level of obesity, based on age-specific reference values and the amount of body fat, in the 14-16 years old group in particular because of lack of skeletal muscle mass and the low physical activity in the children with juvenile rheumatoid arthritis. In summary, patients with JRA should be encouraged to increase their participation in daily activities requiring flexibility instead of using their peripheral joints alone. It also appears necessary to provide appropriate exercise interventions to clinically reinforce hand-related muscle strength and muscle endurance.

\section{ACKNOWLEDGEMENT}

This paper was supported by the Academic Research Fund of Dr. Myung Ki (MIKE) Hong.

\section{REFERENCES}

1) Roth J, Linge M, Tzaribachev N, et al.: Musculoskeletal abnormalities in juvenile idiopathic arthritis—a 4-year longitudinal study. Rheumatology (Oxford), 2007, 46: 1180-1184. [Medline] [CrossRef]

2) van Brussel M, Lelieveld OT, van der Net J, et al.: Aerobic and anaerobic exercise capacity in children with juvenile idiopathic arthritis. Arthritis Rheum, 2007, 57: 891-897. [Medline] [CrossRef]

3) Felin EM, Prahalad S, Askew EW, et al.: Musculoskeletal abnormalities of the tibia in juvenile rheumatoid arthritis. Arthritis Rheum, 2007 , 56: 984-994. [Medline] [CrossRef]

4) Lelieveld OT, Armbrust W, van Leeuwen MA, et al.: Physical activity in adolescents with juvenile idiopathic arthritis. Arthritis Rheum, 2008 , 59: 1379-1384. [Medline] [CrossRef]

5) Takken T, van der Net J, Kuis W, et al.: Physical activity and health related physical fitness in children with juvenile idiopathic arthritis. Ann Rheum Dis, 2003, 62: 885-889. [Medline] [CrossRef]

6) Klepper SE, Darbee J, Effgen SK, et al.: Physical fitness levels in children with polyarticular juvenile rheumatoid arthritis. Arthritis Care Res, 1992, 5: 93-100. [Medline] [CrossRef]

7) Ward TM, Sonney J, Ringold S, et al.: Sleep disturbances and behavior problems in children with and without arthritis. J Pediatr Nurs, 2014, 29: 321-328. [Medline] [CrossRef]

8) Sandstedt E, Fasth A, Eek MN, et al.: Muscle strength, physical fitness and well-being in children and adolescents with juvenile idiopathic arthritis and the effect of an exercise programme: a randomized controlled trial. Pediatr Rheumatol Online J, 2013, 11: 7. [Medline] [CrossRef]

9) Long AR, Rouster-Stevens KA: The role of exercise therapy in the management of juvenile idiopathic arthritis. Curr Opin Rheumatol, 2010, 22: 213-217. [Medline] [CrossRef]

10) Tarakci E, Yeldan I, Baydogan SN, et al.: Efficacy of a land-based home exercise programme for patients with juvenile idiopathic arthritis: a randomized, controlled, single-blind study. J Rehabil Med, 2012, 44: 962-967. [Medline] [CrossRef]

11) España-Romero V, Artero EG, Santaliestra-Pasias AM, et al.: Hand span influences optimal grip span in boys and girls aged 6 to 12 years. J Hand Surg Am, 2008, 33: 378-384. [Medline] [CrossRef]

12) Essendrop M, Schibye B, Hansen K: Reliability of isometric muscle strength tests for the trunk, hands and shoulders. Int J Ind Ergon, 2001 , 28 : 379-387. [CrossRef] 
13) DiNucci J, McCune D, Shows D: Reliability of a modification of the health-related physical fitness test for use with physical education majors. Res Q Exerc Sport, 1990, 61: 20-25. [Medline] [CrossRef]

14) Perret C, Poiraudeau S, Fermanian J, et al.: Validity, reliability, and responsiveness of the fingertip-to-floor test. Arch Phys Med Rehabil, 2001, 82: 1566-1570. [Medline] [CrossRef]

15) Kainu A, Lindqvist A, Sarna S, et al.: Intra-session repeatability of FET and FEV6 in the general population. Clin Physiol Funct Imaging, 2008, 28: 196-201. [Medline] [CrossRef]

16) Gibson AL, Holmes JC, Desautels RL, et al.: Ability of new octapolar bioimpedance spectroscopy analyzers to predict 4-component-model percentage body fat in Hispanic, black, and white adults. Am J Clin Nutr, 2008, 87: 332-338. [Medline]

17) Lindehammar H, Lindvall B: Muscle involvement in juvenile idiopathic arthritis. Rheumatology (Oxford), 2004, 43: 1546-1554. [Medline] [CrossRef]

18) Nascimento RO, Ferreira LF, Goulardins JB, et al.: Health-related physical fitness children with severe and moderate developmental coordination disorder. Res Dev Disabil, 2013, 34: 4222-4231. [Medline] [CrossRef]

19) Schanberg LE, Gil KM, Anthony KK, et al.: Pain, stiffness, and fatigue in juvenile polyarticular arthritis: contemporaneous stressful events and mood as predictors. Arthritis Rheum, 2005, 52: 1196-1204. [Medline] [CrossRef]

20) Turcios NL, Fink RJ: Pulmonary manifestations of pediatric diseases. Philadelphia: Elsevier Health Sciences, 2009.

21) Lee HS, Jung YH: A study on spirometry pattern of normal children. Korean J Pediatr, 1997, 40: 1242-1249.

22) Abad VC, Sarinas PS, Guilleminault C: Sleep and rheumatologic disorders. Sleep Med Rev, 2008, 12: 211-228. [Medline] [CrossRef]

23) Reilly JJ: Assessment of body composition in infants and children. Nutrition, 1998, 14: 821-825. [Medline] [CrossRef]

24) Lumeng CN, Saltiel AR: Inflammatory links between obesity and metabolic disease. J Clin Invest, 2011, 121: 2111-2117. [Medline] [CrossRef] 